\title{
Greening Asia's Economic Development
}

\author{
Paul J. BURKE† and Thang N. DO \\ Australian National University, Australia
}

\begin{abstract}
Asia is facing serious environmental challenges including urban air pollution and the effects of global climate change. As a major source of greenhouse gases, what happens in Asia will play a crucial role in determining the extent to which the world warms over coming decades. This paper reviews key environmental challenges faced by the region and the growing opportunities for a transition to a cleaner economy powered by zero-emission energy sources. Economic mechanisms - including emissions pricing, reverse auctions, and renewable portfolio standards with green certificate schemes - have the potential to underpin a much greener development model for the Asian Century.
\end{abstract}

Key words: carbon pricing, energy, market-based instrument, pollution, renewable

JEL codes: N15, Q43, Q52, Q53, Q54, Q56

\section{Introduction}

Asia is central to many of the world's environmental challenges. As a large source of greenhouse gas emissions and due to its rapid economic growth, the region is the world's most important for efforts to address climate change. Without a substantial reorientation of Asia's emissions trajectory there is a high likelihood that global warming will exceed $2^{\circ} \mathrm{C}$. Asia itself would experience serious consequences, including a higher incidence of hot days and threats to low-lying cities from rising sea levels. From Delhi's smog to Indonesia's forest fires, local and regional environmental issues also abound, bringing large costs to human health and the economy.

Fortunately, rapid improvements in clean energy technologies have opened many new possibilities. Solar and wind have become cost-competitive with conventional power generation sources, and further cost reductions are expected as the technologies continue to mature (International Renewable Energy Agency [IRENA], 2020). Energy storage and grid management technologies such as lithium-ion batteries are becoming cheaper and better. Electric vehicles have become central to car manufacturers' plans. The chance thus exists for Asia's energy system to continue to transition toward one that is increasingly reliant on zero-emission technologies. Such a transition would involve sizeable opportunities.

\footnotetext{
†Correspondence: Paul J. Burke, Arndt-Corden Department of Economics, Australian National University, Crawford Building 132, Lennox Crossing, Acton ACT 2601, Australia. Email: paul.j. burke@anu.edu.au
} 
Economic policy mechanisms have a key role to play in facilitating the switch. Carbon pricing is still only applied in a minority of Asian countries, although there has been some recent momentum, with for example Singapore introducing a carbon tax in 2019. Countries and sub-national jurisdictions have also pursued approaches such as reverse auctions for clean energy and green certificate schemes. All of these approaches have the potential to be used in increasingly scaled-up ways. Nevertheless, the challenges involved in rapidly decarbonizing remain vast.

A rapid transition to low-emission energy will rely crucially on cross-border trade. Solar and wind energy generation, as well as complementary technologies such as batteries and electric vehicles, are technology- and capital-intensive and rely on international supply chains. Openness to imports is vital for rapid adoption. Improvements in high-voltage direct current (HVDC) cables have also broadened the opportunities for cross-border electricity trade, for example sales of electricity from sunny and windy locations to demand centers on the other side of an international border. Yet trade barriers and regulatory restrictions, often motivated by a desire to boost energy selfsufficiency, are slowing the pursuit of these opportunities. There is substantial scope for improving cross-border trade opportunities in order to speed the process of regional decarbonization.

This paper will review the opportunities and challenges for a greening of Asia's economic development, with a focus on the energy sector. Section 2 will review Asia's environmental challenges, and section 3 will discuss the improving technological opportunities to reduce emissions. Economic implications of these opportunities are discussed in section 4 and the future of fossil fuels in section 5. Key economic policy mechanisms are reviewed in section 6. Section 7 discusses the importance of international trade. Concluding comments are also presented.

\section{Asia's Environmental Challenges}

Addressing climate change is a massive global challenge. The world has already warmed by $1^{\circ} \mathrm{C}$ and is on track to reach about $3^{\circ} \mathrm{C}$ of warming by the end of the century in the absence of ambitious new mitigation efforts (Climate Action Tracker, 2020). The climate will only settle at a new equilibrium after the world reaches netzero anthropogenic emissions of greenhouse gases. Decarbonization is thus at the forefront of the world's, and Asia's, environmental priorities.

The world's largest emitter of greenhouse gases is China, which accounted for $28 \%$ of global carbon dioxide $\left(\mathrm{CO}_{2}\right)$ emissions from fuel combustion in 2017 (International Energy Agency [IEA], 2019a). India accounted for 7\%, and Japan 3\%. If currently stated policies are implemented and continued, the IEA (2019b) foresees that India and China alone will account for about half of the global growth in energy use over the period to 2040. If Asia's energy use trajectory remains emissions intensive, the world would be on track for a major disruption to the climate.

Table 1 uses the Kaya (1989) identity to investigate the underlying factors explaining $\mathrm{CO}_{2}$ emissions from fuel combustion for China, India, Indonesia, Japan, 


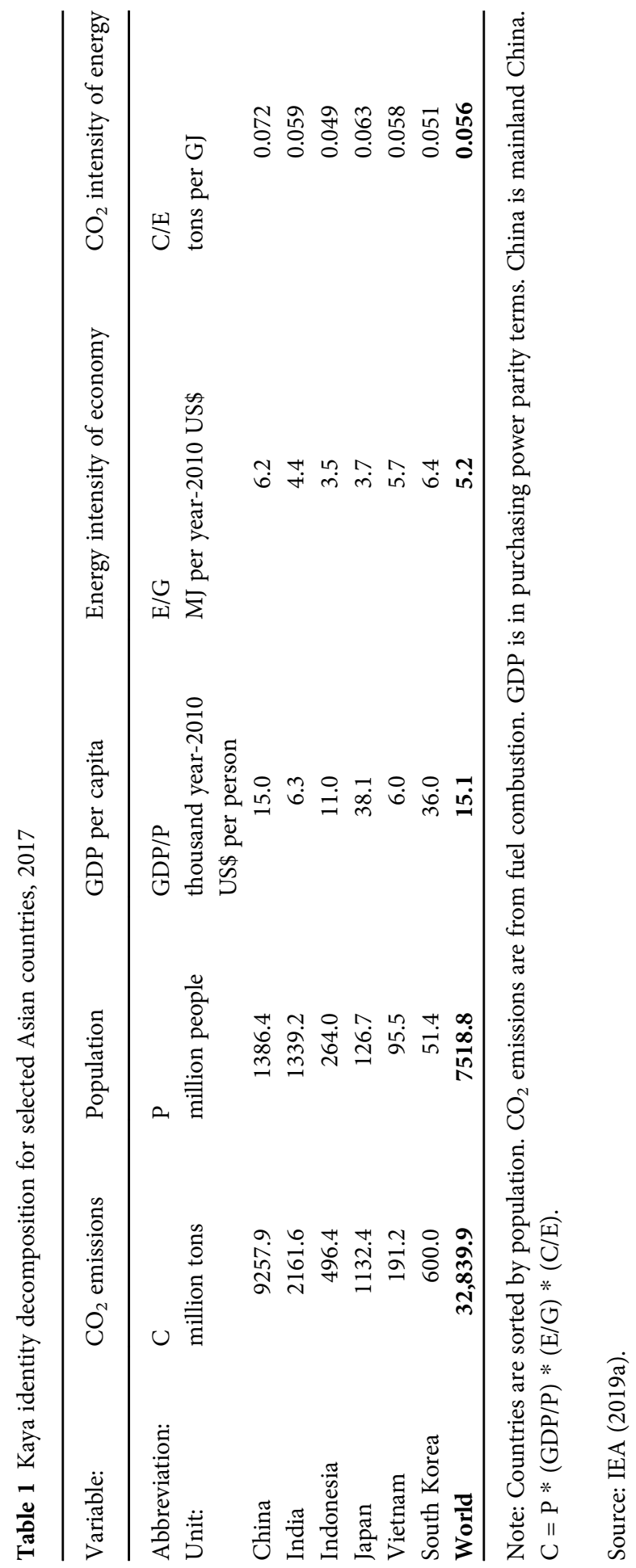


Vietnam, and South Korea in 2017. This identity specifies emissions as a multiplicative function of population $(P)$, gross domestic product per capita $(G / P)$, the energy intensity of gross domestic product $(\mathrm{E} / \mathrm{G})$, and the carbon intensity of energy $(\mathrm{C} / \mathrm{E})$. The six countries account for more than two-fifths of the world's $\mathrm{CO}_{2}$ emissions from fuel combustion. The data show that South Korea and China have relatively energy-intensive economies. China has a particularly high carbon intensity of energy, which is primarily due to heavy dependence on coal.

Asia is highly vulnerable to climate change. The region has a large number of lowlying cities that are threatened by rising sea levels, from Dhaka to Shanghai. Global sea levels are rising by about $3 \mathrm{~mm}$ per year (NASA, 2020). Increases in the number of droughts and hot days pose threats to human health, productivity, agricultural yields, and food security. Climate change is leading to a strengthening of storms, with implications for countries such as the Philippines and Vietnam. The melting of the Himalayan glaciers is threatening water supplies in India and Pakistan (Wester et al., 2018) and ocean acidification and warming are affecting fish stocks and coral reefs. The poor and near-poor are particularly exposed to the effects of climate change given that they are less able to afford adaptation measures (Vinke et al., 2017).

Local air pollution is also a serious challenge. Bangladesh, Pakistan, and Mongolia are the world's worst-performing countries in terms of average exposure to ambient particulate matter $2.5\left(\mathrm{PM}_{2.5}\right)$ (IQAir, 2020), with Afghanistan and India also performing poorly. Air pollution is also a worsening issue in rapidly developing cities such as Hanoi and Jakarta. Fires in Indonesia contribute to major episodes of transboundary pollution. Health effects from exposure to polluted air are serious: Greenstone and Fan (2018) estimate that average life expectancy would be about 4 years longer in Bangladesh and 3 years longer in China, for example, if the World Health Organization guidelines on $\mathrm{PM}_{2.5}$ were not exceeded.

Asia faces numerous other environmental challenges. Human activities are causing species extinctions and a contraction in animal headcounts on land and at sea (WWF, 2018). Deforestation has been continuing in countries such as Indonesia, although at a slowing rate. Water pollution blights many Asian rivers and inland water bodies, while oceans are being polluted by plastics and other substances. Soil pollution is compromising food supplies and human health in China and elsewhere (RodríguezEugenio et al., 2018). Overextraction of natural resources, from fish stocks to underground water, is widespread, especially when resources are open-access in nature. In Jakarta, unpermitted groundwater extraction has contributed to parts of the city subsiding by several meters or more, exposing residents to worsening floods (Rahman et al., 2018).

There are also Asian environmental success stories. Japan's urban air pollution has reduced substantially, and in recent years its $\mathrm{CO}_{2}$ emissions from fuel combustion have also declined. Beijing has achieved a reduction in its notorious air pollution, although highly polluted days still occur (IQAir, 2020). China and India have successfully reforested large areas of land. Indoor air pollution has reduced due to substantial progress toward universal access to modern energy forms such as 


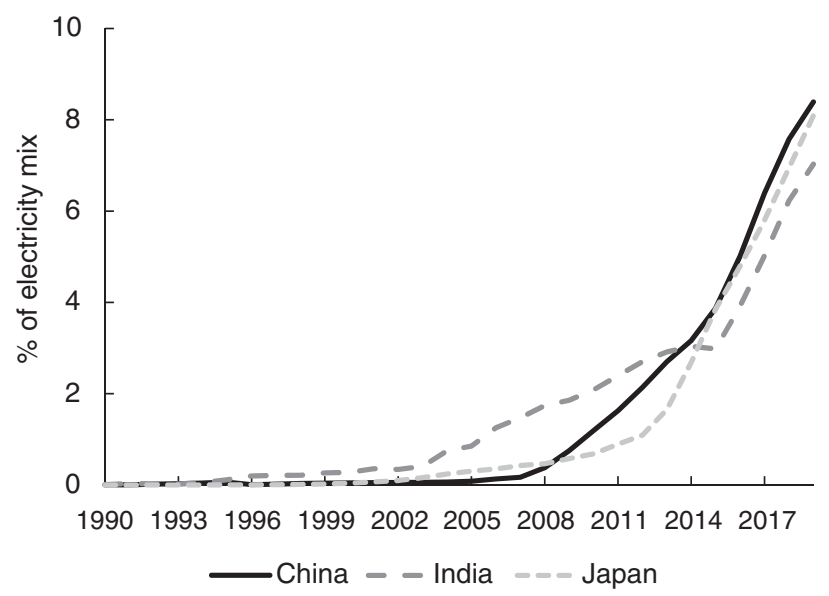

Figure 1 Solar plus wind share of the electricity mix, 1990-2019. China is mainland China. Source: BP (2020).

electricity and liquefied petroleum gas. Countries such as Vietnam have implemented green growth strategies and a number of relevant policy mechanisms, and there has been growing awareness among the public and the corporate sector about environmental issues.

\section{Technological Opportunities}

\section{Solar and wind}

A key route for achieving large-scale reductions in $\mathrm{CO}_{2}$ emissions from the electricity sector is to reduce the carbon intensity of energy sources. This means switching from highly emitting fuels - coal, oil, and natural gas - to low-emission options such as solar, wind, geothermal, and nuclear power. Outside the region, adoption of zero-carbon energy technologies has been the main way that countries such as Sweden and Denmark have achieved large-scale emissions reductions (Burke, 2012).

Cost declines and technological improvements have meant that solar and wind are shaping to be key pillars of the future global electricity system. Figure 1 shows the contributions of solar and wind to the electricity mixes of three large Asian countries: China, India, and Japan. The technologies together contributed $7-8 \%$ of electricity generation in each of these countries in 2019, up from $0 \%$ at the turn of the century (to zero decimal places). While this remains a minority contribution, the upward trends are expected to continue. Intermittent renewables have arrived as mainstream sources of electricity.

Most other Asian countries are further behind. The two technologies contributed only $0.1 \%$ to Indonesia's electricity supply in 2019 , although geothermal and biomass contributed another $6 \%$. Vietnam experienced an initial solar photovoltaic (PV) 
installation boom in 2019, with more than 4 gigawatts (GW) of new PV capacity installed (Do et al., 2020). Investments in utility-scale solar plants have also started to be seen in other lower-middle income countries such as Cambodia and Myanmar.

Globally, 8\% of electricity generation was from solar and wind in 2018. Nuclear power contributed $10 \%$ (BP, 2020), a share that has generally been declining due to safety concerns and the high cost and slow build times of nuclear power stations. In contrast, solar panels are quick and easy to install. The modular nature of solar PV also means that the technology is easily scalable; it can be installed at a micro scale or in an expansive array. Global investment patterns suggest that the contribution of solar plus wind is almost certain to overtake the contribution of nuclear power in the next few years.

Most Asian countries have renewable energy targets, with for example Pakistan aiming to source $30 \%$ of its electricity from solar, wind, small hydro, and biomass by 2030 and another 30\% from large-scale hydro. China is targeting a 35\% renewable electricity share by 2030 , Japan a $22-24 \%$ share by 2030 , and Thailand a $25 \%$ share by 2037. India is aiming to have $450 \mathrm{GW}$ of renewable generation capacity by 2030 . And so on. While levels of ambition vary, goals involving a pivot to renewables have swept the region.

All countries have solar and wind generation potential, with some better endowed than others. China and Mongolia have vast solar and wind resources, and Japan and South Korea have abundant opportunities in offshore wind. While countries that are further from the equator experience winter lulls in solar insolation, wind speeds tend to be faster. Equatorial countries have reasonable year-round solar conditions, although the solar resource of Indonesia is lower than in countries in the Mekong region, which contributes to generation costs being higher (Lee et al., 2019). In addition to domestic opportunities, Asian countries have opportunities to capitalize on offshore and international sites for renewables generation by investing in HVDC cable connections (Cheng et al., 2019).

A major issue is the need to manage the intermittent nature of these resources. Demand-side management, using time-varying prices and other approaches, is a useful means of increasing the flexibility of the system. There are also important roles for energy storage and dispatchable generation. Electric vehicles can be used to help balance the grid (Glitman et al., 2019), a potential that can be enhanced by the application of time-varying electricity tariffs to incentivize vehicle owners to charge up when supply is abundant and feed into the grid at times of scarcity. The dominant form of energy storage is currently pumped hydro, which involves pumping water up an incline when power is cheap and then using the water to turn hydro turbines when power is scarce. Asia has many suitable sites for off-river pumped-hydro energy storage (Blakers et al., 2019).

There are numerous other strategies for managing the intermittency issue and avoiding the situation of solar and wind output being curtailed, as has been seen in countries such as Japan. Expanding the reach and degree of interconnectivity of electricity grids, both domestically and internationally, would help to ensure available 
supply is fully utilized. Diversification between solar and wind also helps, as their generation profiles are often negatively correlated. Improvements in grid management are also vital, for example via use of prediction technologies and reforms to the design of wholesale markets to ensure accurate price signals on a highly timegranular basis. Central planning of transmission and distribution infrastructure, including adequate links to renewable energy zones, can also play a large role. Transmission infrastructure takes longer to install than a solar or a wind farm, and the best solar and wind sites are not likely to be developed without adequate transmission infrastructure.

\section{Other emissions reduction opportunities}

The primary solution to reducing fuel-based emissions outside the electricity sector is a fairly apparent one: electrification. The road transport sector accounts for $11 \%$ of $\mathrm{CO}_{2}$ emissions from fuel combustion from East, Southeast, and South Asia (IEA, 2019a). Electric vehicles, if powered by low-carbon electricity from the grid or rooftop solar panels, have the potential to greatly reduce these emissions. China is currently dominant in the global electric vehicle purchase numbers, with annual sales of electric cars equaling 1.1 million in 2019 (IEA, 2020a). More generally, sales are likely to take off once cost parity with internal combustion engine vehicles is reached. There is substantial scope for government policy to accelerate a transition to cleaner forms of transport.

There are also emissions reduction opportunities in the manufacturing sector. Electrification is an option for some processes, and researchers are working on approaches using green hydrogen - produced by splitting water by electrolysis, powered by zerocarbon electricity. While costs remain uncompetitive at present, the governments of Japan, South Korea, and China have each expressed interest in fostering the market for hydrogen, with the Basic Hydrogen Strategy of Japan targeting a 75-fold increase in hydrogen use by 2030 across industry, transport, and other sectors of Japan's economy.

There are also options for the decarbonization of heating and cooking, including by electrification through the use of electric heat pumps and cooking appliances. Decarbonization of aviation and shipping is challenging, with electrification and zerocarbon fuels being key technology pathways. From an economic point of view it would be ideal for an adequate carbon price signal to be in place to encourage research into and development of the best available zero-carbon energy solutions across the economy.

Energy efficiency improvements are often a low-cost way of reducing emissions, particularly in rapidly growing economies where additional investments in energy provision infrastructure would otherwise be needed. There are many opportunities for improving energy efficiency in Asia, for example via accelerating the adoption of lightemitting diodes. Electrification also helps in improving energy efficiency (Jacobson et al., 2017). 
Emission reductions outside the energy sector are also needed. Ending deforestation and improving the management of peatland are vital. While reducing emissions from agriculture is often challenging, low-emission fertilizers and the rise of meat substitutes offer opportunities (Ritchie et al., 2018). Difficulties in reducing emissions in some settings mean that other approaches - including carbon capture, use, and storage - will be needed if the world is to have much chance of achieving deep decarbonization.

\section{New Economic Opportunities from Renewables}

Mitigation of anthropogenic climate change has traditionally been regarded as a costly endeavor. However the improvements in solar, wind, and other technologies have opened opportunities to switch away from fossil fuels while occurring zero or little in the way of additional costs. Given that power stations need to be replaced over time anyway, why not go for cost-competitive options that have zero emissions? The same logic applies to other capital equipment such as passenger vehicles. Much of the challenge is in creating an investment environment that is best able to capitalize on new zero-carbon opportunities.

The changing economics of the energy sector have opened the way for new comparative advantages. For instance the solar- and wind-rich Gobi Desert, shared by Mongolia and China, could become a major center of electricity generation. While solar and wind projects create the potential for income and job creation in rural and remote areas, the extent to which local populations benefit depends on factors such as land ownership and the form of community participation.

Some changes in the location of energy-intensive manufacturing activities may be expected. Data centers could be expected to congregate near solar- and wind-abundant sites, for example. Some minerals processing may also move to such sites, especially when these coincide with the location of ores. This phenomenon is not likely to affect most manufacturing, though, as other considerations such as distance-to-market and labor force availability are important. Renewable energy can also be efficiently transported via HVDC cables.

A feature of solar and wind power is that once the generation capacity is in place, electricity can be produced at a marginal cost that is equal to or near zero. This helps to lower wholesale electricity prices via what is known as the merit-order effect. As adoption of these technologies increases, cheaper electricity will be able to power increased use of a range of energy-using devices, from air-conditioners to electric transport modes.

In addition to undercutting the need for investments in fossil fuel infrastructure, solar and wind may be able to reduce the need for new on-river hydropower dams in regions such as the Mekong. This would help to avoid the sizeable environmental and social costs of these projects. Solar and wind are quite flexible in their siting given that the underlying resources are large relative to human needs (and noting that solar panels can be mounted on rooftops). Ideally, new energy projects would be sited in 
locations that have the lowest overall costs, with environmental and social costs being fully considered.

\section{Prospects for Fossil Fuels}

While renewables are making inroads, coal remains the principal source of electricity generation in key Asian economies. In 2019, coal contributed 65\% of China's electricity generation, down from a peak of $81 \%$ in 2007 . For India, coal's contribution was $73 \%$ of the electricity mix in 2019, down from 77\% in 2016 (BP, 2020). New coal-fired power stations continue to be built, although in falling numbers. The six countries in Table 1 are the world's top six in terms of current construction of coal-fired power station capacity, accounting for $87 \%$ of the global total as of January 2020 (Global Energy Monitor, 2020). There is a risk that these assets will become stranded due to both increasing competition from alternative energy sources and growing concerns about the negative externalities from coal use.

Fossil fuels also continue to make a major contribution to the overall primary energy mix. Coal contributed 64\% of China's primary energy in 2017 and $44 \%$ of India's (IEA, 2019c). Natural gas use has generally been increasing, with the industry being transformed globally by the rise of liquefied natural gas and booms in both offshore extraction and unconventional extraction. The Asian spot price for natural gas has crashed, with the long-standing "Asian premium" for this product being eroded.

Under stated policies the IEA (2019b) expects coal use to stagnate over the next two decades, both globally and in Asia. Growth in the use of oil and natural gas was anticipated, although the COVID-19 crisis has subsequently intervened. It is possible that thermal coal use will never fully recover from the COVID-19 decline, especially if alternative technologies continue their rapid improvements. The long-term future of the use of oil for road transport is also looking precarious given the rise of electric alternatives. The IEA (2019b) foresees a large decline in global oil use under a scenario in which serious efforts are taken to meet the Paris Agreement objective of limiting global warming to well below $2^{\circ} \mathrm{C}$.

Despite the improvements in renewables, the fossil fuel industry is certainly not done with yet. Fossil fuel prices have the ability to fall in response to pressure from new energy sources. Coal-fired generation also remains relatively cost-competitive in locations such as Java (Indonesia) if external costs are ignored and as a result of the existence of government policies that push the coal price down and solar costs up (Burke et al., 2019). The fossil fuel industry is a powerful incumbent in many Asian countries, with state-owned enterprises heavily invested. The private sector also continues to invest in fossil fuel projects. There is a lot of money on the line, and many regionally focused jobs. Renewables should expect vigorous competition in both economic markets and the political sphere.

Countries with export models that are largely or partially centered on fossil fuels, such as Indonesia, are exposed to potential declines in external demand for products such as coal. Given its rich endowments in renewable resources and its lead in the 
manufacturing of clean technologies, perhaps the biggest geopolitical winner from the rise of clean energy will be China. China is also rich in rare earths, vital inputs to the production of clean energy technologies.

A transition challenge exists for workers and communities whose livelihoods currently rely on fossil fuel extraction, especially in the coal sector. A partial solution is to facilitate investment in solar, wind, and energy storage in coal-mining regions. Social safety nets and retraining opportunities are also crucial. There is scope for economists to carry out more research into approaches that work best in supporting livelihoods during the ongoing energy transition.

\section{Economic Policy Mechanisms}

Environmental problems arise largely as a result of negative externalities. For this and other reasons, governments have a strong rationale to implement policies to reduce emissions. While private-sector efforts such as RE100 - under which corporations pledge to power their activities with renewable electricity - are important, public policy interventions are the primary means via which large-scale emissions reductions can be achieved. This section discusses key economic mechanisms being used in Asian countries and elsewhere: emissions pricing, reverse auctions, and renewable portfolio standards (RPSs) with green certificate schemes.

\section{Emissions pricing}

Economists' primary prescription for pollution problems is to either adequately allocate property rights or to introduce a price that acts as a proxy for the negative external costs of pollution. If an emissions price is in place, a market-based economy will have an incentive to steer itself in a greener direction, with Best et al. (2020) finding a large negative association between the use of carbon pricing and subsequent emission growth rates. If introduced early in the development process, emissions pricing can help countries avoid the worst of the pollution problems experienced by countries such as China and India (Burke, 2014).

Pricing of greenhouse gas emissions via either an emissions trading scheme (ETS) or a carbon tax remains rare in the region. Only four countries across East, Southeast, and South Asia had a carbon price by mid-2020 (World Bank, 2020):

- Japan has a small carbon tax, set at US\$3 per ton $\mathrm{CO}_{2}$. The cities of Tokyo and Saitama also run baseline-and-credit ETSs.

- South Korea introduced an ETS in 2015. As of late 2019 the permit price was about US\$29 per ton $\mathrm{CO}_{2}$.

- Singapore introduced a carbon tax of about US\$4 per ton $\mathrm{CO}_{2}$ in 2019.

- China has run sub-national pilots and is working toward national implementation of its ETS, initially to be applied to the power sector. 
A number of other Asian economies, including Vietnam, have considered pricing carbon, although have yet to move to implementation. In 2019 Indonesia established an environmental fund management agency under its Ministry of Finance to pursue the use of green fiscal instruments. While not a carbon price, India has imposed a charge on coal since 2010, in part to encourage clean energy.

A carbon tax is preferable over an ETS in a few ways. A tax is administratively simpler given that it does not involve permit trading, and is a better fit for many countries' revenuecollection architectures given that it can be collected by the national tax agency. A tax also avoids the price uncertainty associated with an ETS, which helps to simplify investment analyses. While uncertainty over the overall emissions level in any individual year remains, this is less of an issue than it would be for a pollutant for which the marginal damage function is steep (Weitzman, 1974). One way to address the issue is to establish a mechanism via which a carbon tax can be increased if emissions are not falling adequately. ${ }^{1}$

Two key hurdles for broader application of carbon pricing are (i) technical readiness in terms of emissions measurement and monitoring and revenue collection, and (ii) political feasibility. The issue of technical readiness is particularly pertinent in developing countries, although simple schemes applied to only large emitters can be feasible. Political feasibility varies by country, with experience showing that design features such as revenue recycling can enhance popularity. Carbon pricing packages can also be designed to ensure progressivity.

The pricing of emissions is also useful for tackling local pollution problems. China first introduced pollution charges in the 1980s, and countries including Thailand, Philippines, and Malaysia introduced wastewater fees in the 2000s. In a 2012 reform package Vietnam introduced environmental taxes on products including plastic bags and pesticides. Environmental tax rates have tended to be quite low throughout the region, however. Compliance issues have also arisen.

Some Asian countries do the opposite of pricing emissions, instead maintaining distortions that encourage fossil fuel production and consumption. There have been some reforms in recent years, with for example Indonesia raising consumer prices for gasoline, diesel, and also retail sales of electricity. Yet distortions remain, including a domestic market obligation for coal producers in Indonesia that depresses the local coal price and encourages coal use.

\section{Reverse auctions}

The primary approach for procuring new renewable projects has traditionally been the use of feed-in tariffs, whereby electricity from new installations can be sold at a fixed price over a certain period. Such an approach can certainly spur renewables uptake, as seen in Vietnam's solar installation boom in 2019 (Do et al., 2020). In recent years, however, an alternative approach has become increasingly popular: reverse auctions for power purchase agreements (PPAs). The auction winners are those projects that submit the lowest price offers, with their projects then being awarded a PPA that typically extends for about 20 years. 
India is among countries that led the way in reverse auctions for both utility-scale solar (from 2010) and wind (from 2017). The approach has helped drive prices down to well below the previously applied feed-in tariffs, and to such low levels that they have begun to undercut the costs of new and even existing coal-fired power stations (Burke et al., 2019). The lowest bid in a Solar Energy Corporation of India (SECI) national auction in 2019 came in at just US\$0.036 per kilowatt-hour (kWh). That is cheap. A SECI auction for solar plus storage in early 2020 - for the delivery of electricity at both off-peak and peak times - also delivered low prices.

Reverse auction successes are spreading. In 2019, Cambodia recorded an auction price of only US $\$ 0.039$ per $\mathrm{kWh}$ for a $60-\mathrm{MW}$ solar PV installation in Kampong Chhnang province, with 26 bids submitted. This project benefitted from support from the Asian Development Bank (ADB) and World Bank (Keating, 2019). A reverse auction in Bangladesh in 2019 saw the winning bid come in at US\$0.075 per kWh, a record low for the country's solar sector (Islam, 2019). China, Malaysia, and Japan are among other Asian countries to have commenced using reverse auctions.

Reverse auctions work best when a supportive policy environment is in place and the investment context is de-risked as much as possible so as to facilitate the mobilization of private financing. Take-or-pay requirements and payment security mechanisms are among the tools available for reducing off-take and other risks. For small-scale installations, feed-in tariffs or net metering arrangements are typically preferred over auctions, as they avoid the transaction costs that would be associated with auctions.

\section{Renewable portfolio standards}

Another mechanism for encouraging renewables uptake is the RPS - a requirement that a certain level or share of renewables be achieved in each given year. Compliance requirements are typically imposed on retail suppliers of electricity. In flexibly designed schemes, obligations can be met using tradable renewable energy certificates, also called "green certificates." Each certificate represents a certain quantity of electricity from renewable sources. A market for green certificates then forms, with the supply side being the renewable generators and the demand side being the electricity retailers and perhaps other entities. If a country has a renewables target, a well-managed RPS is a direct and efficient mechanism for achieving it.

RPSs and green certificates are becoming more widely used in the region. South Korea's RPS required 2\% of power to come from renewable and new energy in 2012, rising to $10 \%$ in 2023 , and with obligations able to be met by green certificates. India has RPS and green certificate schemes, although utilities have not met all of their required obligations. China has announced a new RPS to apply from 2020, with requirements by province and the use of green certificates. The Philippines also has an RPS.

By guaranteeing a minimum level of demand for renewable energy, an RPS helps reduce the uncertainty faced by renewables developers at both the initial investment stage and the off-take stage. This helps to lower financing costs and deliver cheaper 
projects. However, green certificate schemes require adequate monitoring and verification. As the case of India demonstrates, they can fail to work well in the absence of strong institutional support.

\section{Comparing the instruments}

There is no single policy tool for reducing emissions. Instead, there are multiple approaches that are available. Emissions pricing has an advantage over an RPS in that it provides a broad signal to all relevant agents to reduce emissions when doing so is cheaper than the per-unit emissions price. An RPS does not incentivize greater use of natural gas relative to coal, for example. Nevertheless an RPS is often more politically viable. A key advantage is that an RPS does not have the word "tax" or "price" in its name. Renewables are typically more popular than either emissions reduction policies or new taxes.

An advantage of reverse auctions over standard feed-in tariffs is that competitive forces in an auction can help to drive prices down. One challenge is that in some instances auction winners seek to enter ex-post negotiations to revise their feed-in price upward or gain other concessions. Such risks can be reduced by suitable qualification requirements and procurement rules (IRENA, 2019). New auctions can also be run in the event of under-delivery.

\section{The Importance of Internationalism}

In a world without borders there would be substantially more in the way of cross-border flows in electrons - from the sites with the best solar, wind, and hydro resources to major demand centers. There would also be sizeable international flows in technology, expertise, and finance. The result would be a cheaper and quicker transition to low-cost renewables.

In reality there are impediments to trade. Solar panel costs in India have been inflated by the imposition of a two-year safeguard duty on imports from countries including China and Malaysia from 2018. This contributed to a decline in solar installations in 2018-2019 (Gupta, 2019) while achieving little in the way of improved domestic manufacturing capabilities (Saur News Bureau, 2019). Indonesia imposes local content requirements on solar projects, which leads to domestic cost inflation and inhibits the installation market. Malaysia is among other countries to favor local content for solar PV.

There are also barriers to cross-border electricity trade. In 2018 Singapore did not import any electricity, despite its neighbors having generation opportunities and the fact that Singapore is a trade-oriented nation when it comes to most other goods and services, including oil and natural gas. There are opportunities for the country to make more use of its existing interconnection with Malaysia and also develop new interconnections to import electricity from elsewhere. Indonesia imports a small amount of electricity from Malaysia, but there is a general requirement that imports should not 
lead to "dependence on the procurement of electrical power from other countries" (Government Regulation No. 42/2012). The main underlying reasons for low levels of electricity trade are national energy security concerns and distrust of neighbors. Holdup problems and other issues also mean that cross-border transmission lines are risky investments, so there is typically a large role for government involvement in any such projects.

Internationalism is vital for overcoming these barriers and ensuring a speedy transition to zero-carbon technologies. Multilateral development banks such as the World Bank and ADB have important roles, including ideally in providing technical advice on cross-border electricity trade. There are many opportunities for bilateral cooperation, and regional groups such as the Association of Southeast Asian Nations (ASEAN) have ambitious targets to establish regional power grids. China has ambitious plans for an Asian Super Grid and even a global energy interconnection.

An exception to the generally slow progress on cross-border electricity trade is Laos, which has become one of the world's top-10 exporters of electricity (U.S. Energy Information Administration, 2020). However Laos' electricity exports have mostly been powered by hydro dams, which have brought environmental and social costs. Solar and wind projects offer the potential to avoid some of these costs and also risks associated with changes to hydrological patterns due to climate change and excessive damming (Schmitt et al., 2019).

\section{Conclusion}

Solar and wind power have the potential to boom in Asia over coming years, with energy researchers increasingly emphasizing the possibility of moving toward high penetration levels (e.g. Jacobson et al., 2017; Blakers et al., 2019). Moving in this direction makes sense given that these technologies are now cost-competitive and given the large external costs of fossil fuel use. A key challenge is the intermittency issue, although there are ample opportunities to harness energy storage, prediction, and other technologies to help to manage the system.

While the global COVID-19 recession of 2020 has led to a reduction in global $\mathrm{CO}_{2}$ emissions (IEA, 2020b), it is also leading to delays in the implementation of some renewables projects and in the adoption of low-emission technologies. Governments have an opportunity to place green development priorities at the heart of their economic recovery packages, with a leading priority being investment in infrastructure for the transmission of electricity from the best solar and wind sites to major demand centers. There is, however, a risk that some stimulus spending will flow to fossil fuel projects, especially in countries that have large extraction sectors.

The history of the renewable energy industry shows that well-designed policy approaches can play a key role in bringing costs down. Mechanisms such as reverse auctions have harnessed competitive pressures that have helped new solar and wind projects come in at prices that would have been seen as inconceivably low a decade 
ago. The rise of solar and wind has also been aided by the current low-interest rate macroeconomic environment, which favors capital- over fuel-intensive projects.

Electricity is set to make an increasing contribution to the final energy mix throughout Asia and globally. Yet it is telling that international trade in electricity remains small in most of Asia, with some countries currently having zero trade in electricity with their neighbors. There are many potential gains from trade to be harnessed.

Reducing emissions outside the electricity sector can in some cases be challenging. Electrification is a key part of the solution, and there is enthusiasm for green hydrogen. Strong and sustained demand-side interest will be needed if industries such as green hydrogen and green steel are to scale up and achieve the types of cost reductions that have been achieved for solar and wind.

A reform priority is the expansion of carbon pricing so that clean energy sources are able to compete on a more level playing field. Adoption of simple domestic carbon taxes is the most desirable option, as a regional or even global carbon tax would require a large coordination effort that may well not be successful. There are also other available policy mechanisms, such as the use of green certificates to meet renewable energy targets. Economic instruments are also well suited to enhancing environmental and resource management outside the energy sector, for example:

- Emissions pricing for local pollutants such as discharges into waterways.

- Tradable permit schemes for the extraction of resources such as water.

- Reverse auctions for the rehabilitation of land and the provision of ecosystem services.

The exact details of policy design are important. A carbon price set at a low level and with many exemptions would be less effective than a more rigorous scheme, for instance. The mechanisms discussed in this paper are also not the only approaches available to policymakers. Regulations can play an important role in emission-reduction efforts, and there are other incentive schemes such as the use of tax credits. Urban planning is also important, with smart-city designs being a key way of ensuring that technology plays as large a role as possible in the building of a clean and resilient energy system.

The rise of solar and wind power brings some other challenges. Cheap distributed energy can exacerbate resource management issues, for example when solar water pumps are used to extract groundwater (as in India). Solar and wind farms are exposed to natural disasters such as cyclones. It will also be necessary for industry and governments to develop more of a focus on end-of-life recycling and waste management for products such as solar panels and batteries.

Rapid adoption of zero-carbon energy in Asia would bring substantial benefits in reduced local pollution and a slowing of global climate change. By lowering production costs, industry scale-up in Asia would also assist countries outside the region to realize their own renewable energy ambitions, helping to underpin global action toward 
meeting the aims of the Paris Agreement. However the scale of the climate change challenge remains immense. The expectation of ongoing expansion in global energy use, driven by economic and population growth, makes the task of achieving largescale emissions reductions an imposing one.

\section{Note}

${ }^{1}$ We thank Eiji Hosoda for his suggestion to include a discussion of instrument performance under uncertainty.

\section{References}

Best R., Burke P.J. \& Jotzo F. (2020). Carbon pricing efficacy: Cross-country evidence. Environmental and Resource Economics.

Blakers A., Stocks M., Lu B., Cheng C. \& Stocks R. (2019). Pathway to 100\% renewable electricity. IEEE Journal of Photovoltaics, 9 (6), 1828-1833.

BP (2020). Statistical Review of World Energy. Accessed 17 June 2020. Available from URL: https://www.bp.com/en/global/corporate/energy-economics/statistical-review-of-world-energy. html

Burke P.J. (2012). Climbing the electricity ladder generates carbon Kuznets curve downturns. Australian Journal of Agricultural and Resource Economics, 56 (2), 260-279.

Burke P.J. (2014). Green pricing in the Asia Pacific: An idea whose time has come? Asia and the Pacific Policy Studies, 1 (3), 561-575.

Burke P.J., Widnyana J., Anjum Z., Aisbett E., Resosudarmo B. \& Baldwin K.G.H. (2019). Overcoming barriers to solar and wind energy adoption in two Asian giants: India and Indonesia. Energy Policy, 132, 1216-1228.

Cheng C., Blakers A., Stocks M. \& Lu B. (2019). Pumped hydro energy storage and 100\% renewable electricity for East Asia. Global Energy Interconnection, 2 (5), 386-392.

Climate Action Tracker (2020). Temperatures. Accessed 5 January 2020. Available from URL: https://climateactiontracker.org/global/temperatures

Do T.N., Burke P.J., Baldwin K.G.H. \& Nguyen C.T. (2020). Underlying drivers and barriers for solar photovoltaics diffusion: The case of Vietnam. Energy Policy, 144, 111561.

Glitman K., Farnsworth D. \& Hildermeier J. (2019). The role of electric vehicles in a decarbonized economy: Supporting a reliable, affordable and efficient electric system. Electricity Journal, 32 (7), 106623.

Global Energy Monitor (2020). Global Coal Plant Tracker. Accessed 5 June 2020. Available from URL: https://endcoal.org/global-coal-plant-tracker

Greenstone M. \& Fan C.Q. (2018). Introducing the Air Quality Life Index. Chicago, IL: Energy Policy Institute, University of Chicago.

Gupta U. (2019). Solar set for boom after a gloomy 2019. pv magazine. Accessed 31 December 2019. Available from URL: https://www.pv-magazine-india.com/2019/12/30/solar-set-forboom-after-a-gloomy-2019

International Energy Agency (2019a). CO2 Emissions from Fuel Combustion, 2019. Accessed 4 December 2019. Available from URL: https://webstore.iea.org/co2-emissions-from-fuelcombustion-2019-highlights 
International Energy Agency (2019b). World Energy Outlook 2019. Paris: International Energy Agency.

International Energy Agency (2019c). World Energy Balances and Statistics. Accessed 15 December 2019. Available from URL: https://www.iea.org/data-and-statistics

International Energy Agency (2020a). As the Covid-19 Crisis Hammers the Auto Industry, Electric Cars Remain a Bright Spot. Accessed 15 June 2020. Available from URL: https://www.iea. org/commentaries/as-the-covid-19-crisis-hammers-the-auto-industry-electric-cars-remain-abright-spot

International Energy Agency (2020b). Global Energy Review 2020: The Impacts of the Covid-19 Crisis on Global Energy Demand and $\mathrm{CO}_{2}$ Emissions. Paris: International Energy Agency.

International Renewable Energy Agency (2019). Renewable Energy Auctions: Status and Trends beyond Price. Abu Dhabi: Preliminary Findings.

International Renewable Energy Agency (2020). Renewable Capacity Highlights. Abu Dhabi: International Renewable Energy Agency.

IQAir (2020). 2019 World Air Quality Report. IQAir.

Islam, S. (2019). Metito wins 45-55 MW Bangladesh project with $\$ 0.07 / \mathrm{kWh}$ bid. pv magazine. Accessed 16 December 2019. Available from URL: https://www.pv-magazine.com/2019/08/06/ metito-wins-45-55-mw-bangladesh-project-with-0-07-kwh-bid

Jacobson M.Z., Delucchi M.A., Bauer Z.A. et al. (2017). 100\% clean and renewable wind, water, and sunlight all-sector energy roadmaps for 139 countries of the world. Joule, 1 (1), 108-121.

Kaya Y. (1989). Impact of carbon dioxide emission control on GNP growth: Interpretation of proposed scenarios. Intergovernmental Panel on Climate Change, Response Strategies Working Group, May.

Keating C. (2019). Cambodia's 60MW solar auction draws record-low bid, PV-Tech. Accessed 7 January 2020. Available from URL: https://www.pv-tech.org/news/cambodia-solar-auctiondraws-record-low-bid

Lee N., Flores-Espino F., Cardoso de Oliveira R.P., Roberts B.J., Brown T. \& Katz J.R. (2019). Exploring renewable energy opportunities in select Southeast Asian countries: A geospatial analysis of the levelized cost of energy of utility-scale wind and solar photovoltaics. National Renewable Energy Lab.

NASA (2020). Global Climate Change: Vital Signs of the Planet. Accessed 3 January 2020. Available from URL: https://climate.nasa.gov

Rahman S., Sumotarto U. \& Pramudito H. (2018). Influence the condition land subsidence and groundwater impact of Jakarta coastal area. IOP Conference Series: Earth and Environmental Science, 106, 012006.

Ritchie H., Reay D.S. \& Higgins P. (2018). Potential of meat substitutes for climate change mitigation and improved human health in high-income markets. Frontiers in Sustainable Food Systems, 2, 16.

Rodríguez-Eugenio N., McLaughlin M. \& Pennock D. (2018). Soil Pollution: A Hidden Reality. Rome: Food and Agricultural Organization.

Saur News Bureau (2019). The potholes of 2019 for India's solar drive. Saur Energy International. Accessed 31 December 2019. Available from URL: https://www.saurenergy.com/solarenergy-articles/the-potholes-of-2019-for-indias-solar-drive

Schmitt R.J., Kittner N., Kondolf G.M. \& Kammen D.M. (2019). Deploy diverse renewables to save tropical rivers. Nature, 569 (7756), 330-332. 
U.S. Energy Information Administration (2020). International. Accessed 5 February 2020. Available from URL: https://www.eia.gov/international/data/world

Vinke K., Schellnhuber H.J., Coumou D. et al. (2017). A Region at Risk: The Human Dimensions of Climate Change in Asia and the Pacific. Manila: Asian Development Bank.

Weitzman M.L. (1974). Prices vs. quantities. Review of Economic Studies, 41 (4), 477-491.

Wester P., Mishra A., Mukherji A. \& Shrestha A.B. (2018). The Hindu Kush Himalaya Assessment. Berlin: Springer.

World Bank (2020). Carbon Pricing Dashboard. Accessed 4 January 2020. Available from URL: https://carbonpricingdashboard.worldbank.org/map_data

WWF (2018). Living Planet Report - 2018: Aiming Higher. Gland: WWF. 